\title{
Implementasi Metode Linear Congruential Generator Pada Game Puzzle Kesenian Tari
}

\author{
Diana Nawang Safitri ${ }^{1}$, Iskandar Fitri ${ }^{2}$, Rini Nuraini ${ }^{3}$ \\ ${ }^{1,2,3}$ Informatika, Fakultas Teknologi Komunikasi dan Informatika, Universitas Nasional \\ e-mail: 1diananawangs18@gmail.com, ${ }^{2}$ tektel2001@yahoo.com, \\ 3rini.nuraini@civitas.unas.ac.id
}

\begin{abstract}
Abstrak
Kesenian tari adalah cabang kesenian nusantara yang menggunakan gerakan tubuh dan diperagakan secara berirama yang bertujuan untuk mengekspresikan perasaan atau menyampaikan pesan individu atau kelompok. Pada aplikasi puzzle ini pengguna diberi dua pilihan level yaitu $2 \times 3$ dan $3 \times 3$. Game puzzle ini bertemakan Kesenian Tari di Pulau Jawa yang ditujukan untuk anak-anak berusia 6-10 tahun. Di dalam aplikasi game ini terdapat beberapa gambar dari berbagai provinsi di pulau jawa yang telah diubah kedalam tampilan puzzle yang nantinya pengguna dapat menyusun potongan gambar tersebut. Perancangan ini menerapkan metode Linear Congruential Generator (LCG) sebagai pengacak gambar yang disajikan pada aplikasi ini. Berdasarkan hasil pengujian didapatkan bahwa aplikasi ini berjalan sesuai dengan konsep awal dan penerapan metode berhasil diterapkan.
\end{abstract}

Kata kunci-Kesenian Tari, LCG, Puzzle

\begin{abstract}
Dance is a branch of Indonesian art that uses body movements and is performed rhythmically with the aim of expressing feelings or conveying individual or group messages. In this puzzle application, users are given two-level choices, namely $2 \times 3$ and $3 \times 3$. This puzzle game has the theme of Dance in Java, which is aimed at children aged 6-10 years. In this game application, there are several pictures from various provinces on the island of Java that have been converted into a puzzling view which later the user can arrange the pieces of the image. This design applies the Linear Congruential Generator ( $L C G)$ method as a randomizer for the images presented in this application. Based on the test results, it was found that this application was running in accordance with the initial concept and the application of the method was successfully applied.
\end{abstract}

Keywords - Dance Art, LCG, Puzzle

\section{PENDAHULUAN}

$\mathrm{K}$ eragaman budaya dapat tercermin melalui berbagai macam seni tari yang ada di Nusantara [1]. Kesenian tari merupakan salah satu cabang kesenian dari berbagai provinsi yang ada di Indonesia. Kesenian tari tersebut memiliki ciri khas dari masing-masing provinsi, biasanya kesenian tari memiliki tujuan untuk mengekspresikan atau menyampaikan pesan dari beberapa individu maupun kelompok. Kesenian tari ditampilkan dengan beberapa gerakan tubuh bersama irama yang diiringi dengan bunyi-bunyian atau musik. Kesenian tari juga berfungsi sebagai sarana Keagamaan atau Kepercayaan, sarana upacara adat, sarana pergaulan, sarana hiburan, dan lain-lain.

Puzzle merupakan sebuah permainan modern yang menampilkan potongan-potongan gambar teracak untuk diselesaikan menjadi sebuah gambar yang sempurna [2]. Gambar puzzle 
yang beragam dapat merangsang kreatifitas dan menambah wawasan pengguna dalam menyusunnya [3].

Perancangan game ini mengangkat tema Kesenian Tari di Pulau Jawa. Game puzzle ini berisi gambar kesenian tari dari berbagai provinsi di Pulau Jawa dan terdapat juga penjelasan singkat mengenai tarian tersebut. Pulau Jawa terdiri dari beberapa provinsi, diantaranya Banten, DKI Jakarta, Jawa Barat, Jawa Tengah, Jawa Timur, Daerah Istimewa Yogyakarta.

Perancangan game ini dibangun menggunakan aplikasi Construct 2 yang merupakan aplikasi sederhana untuk pembuatan desain game 2 dimensi yang bersifat "drag and drop" dimana aplikasi ini memiliki fitur membuat game tanpa melakukan programming [4,5].

Adapun metode yang diterapkan yaitu metode Linear Congruential Generator ( $L C G)$ guna membangkitkan bilangan acak sederhana yang dinilai cocok untuk diterapkan dalam pengacakan gambar puzzle saat game dimulai [6,7].

\section{METODE PENELITIAN}

\subsection{Kerangka Penelitian}

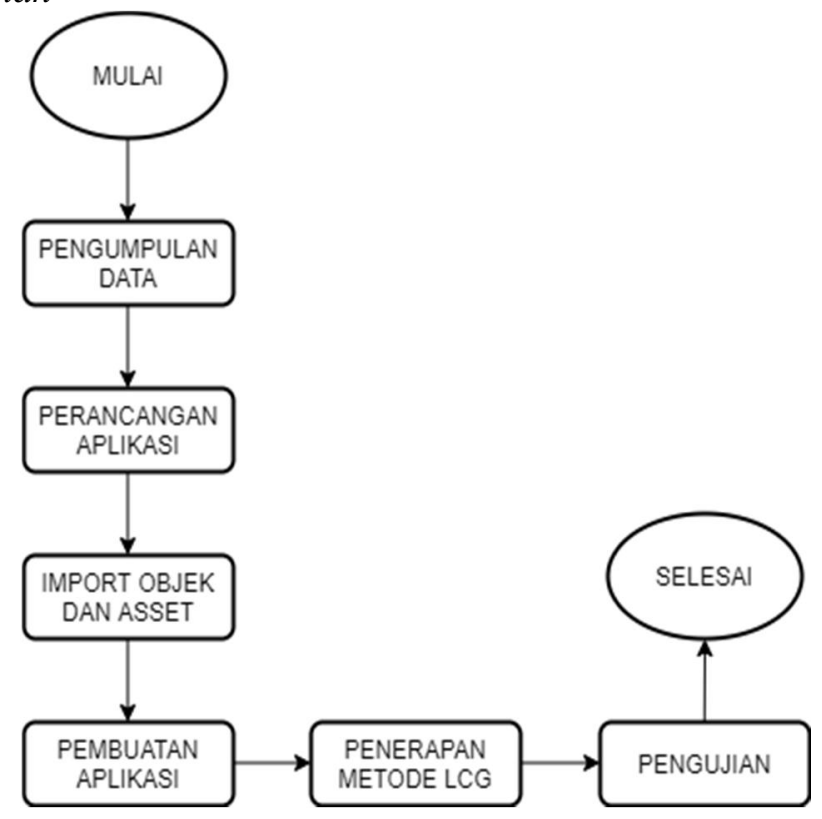

Gambar 1. Flowchart Kerangka Penelitian

Untuk merancang aplikasi yang ingin dibuat, perancang membuat tahapan-tahapan yang akan dilakukan untuk menyelesaikan aplikasi ini, diantaranya:

1. Tahap Pengumpulan Data, tahapan ini dimulai dengan mencari informasi mengenai materi yang akan dibuat dan mencari kebutuhan perangkat atau tools apa saja yang akan digunakan.

2. Tahap Perancangan, tahapan ini digunakan untuk merancang aplikasi agar sesuai dengan konsep yang sudah ditentukan.

3. Tahap Import Objek dan Asset, setelah selesai didesain maka selanjutnya objek dan asset tersebut diimport kedalam tools yang digunakan.

4. Tahap Pembuatan Aplikasi, tahap ini dimulai dengan menggabungkan rancanganrancangan dan objek-objek yang telah dibuat sebelumnya. 
5. Tahap Penerapan Metode $L C G$, metode ini akan diterapkan kedalam aplikasi yang telah selesai dibuat.

6. Tahap Pengujian, setelah aplikasi selesai dibuat maka akan dilakukan pengujian untuk mengetahui adanya masalah yang muncul atau tidak.

\section{2 Perancangan Aplikasi}

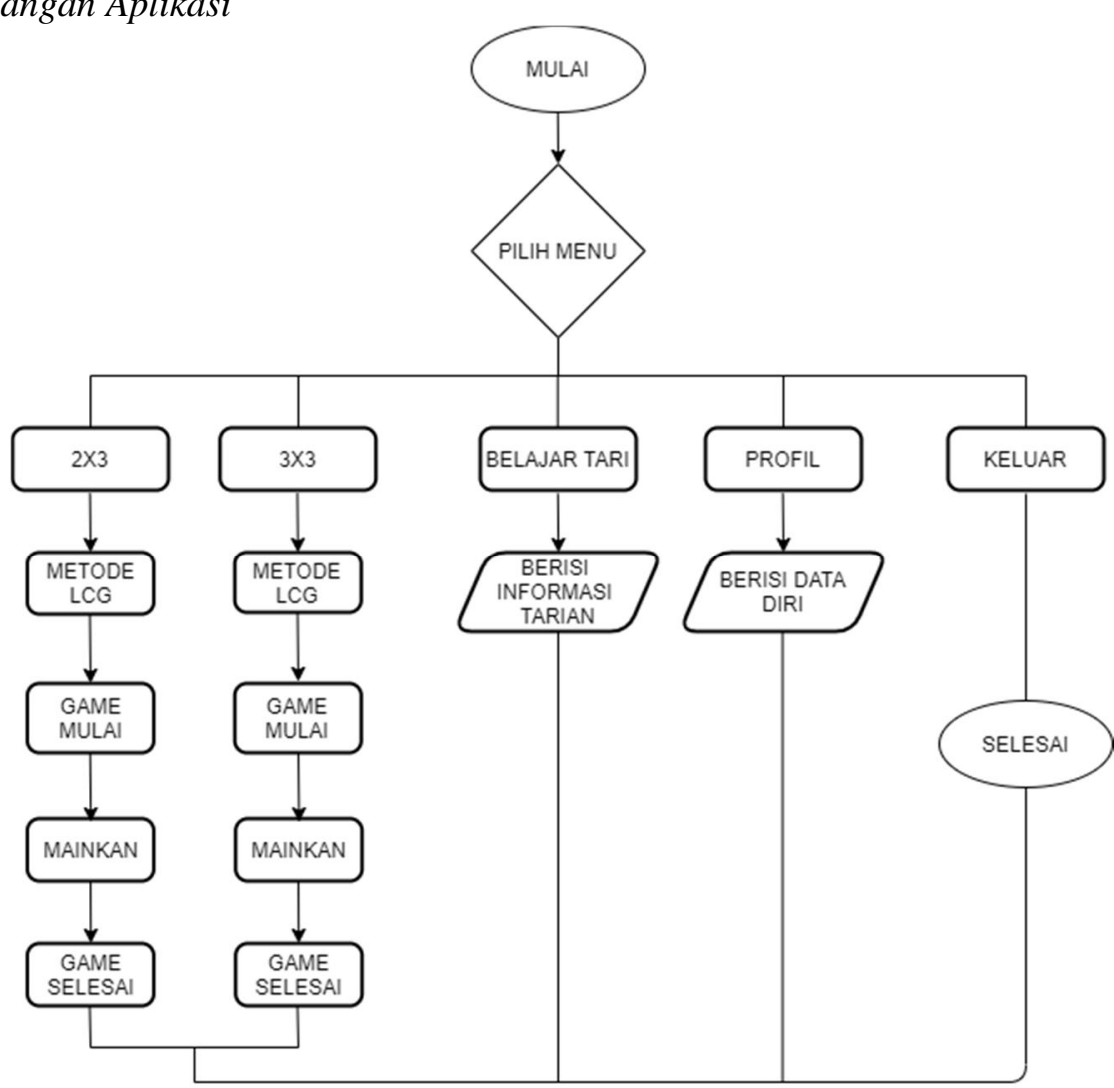

Gambar 2. Flowchart Rancangan Aplikasi

Pada gambar 2, flowchart tersebut menjelaskan mengenai rancangan aplikasi apa saja yang ada didalam aplikasi, diantaranya:

1. Pada tampilan halaman awal terdapat button puzzle yang jika diklik akan menampilkan menu selanjutnya.

2. Pada menu selanjutnya, pengguna dapat memilih pilihan level yaitu $2 \times 3$ atau $3 \times 3$, Belajar Tari, Profil dan Keluar.

3. Level $2 \times 3$ berisi game puzzle yang memiliki potongan gambar dengan ukuran $2 \times 3$.

4. Level $3 \times 3$ berisi game puzzle yang memiliki potongan gambar dengan ukuran $3 \times 3$.

5. Belajar Tari menampilkan beberapa informasi singkat mengenai Kesenian Tari yang ada di Pulau Jawa.

6. Jika telah menyelesaikan permainan maka akan kembali ke menu utama dan dapat memilih menu keluar.

\section{3 Metode Linear Congruential Generator (LCG)}

Metode $L C G$ bila diartikan sama dengan membangkitkan bilangan acak yang mudah diterapkan, mudah dipahami, dan sederhana[8].

Adapun rumus dari metode $L C G$, yaitu: 
Keterangan:

$$
X_{b}=\left(p\left(X_{b-1}\right)+q\right) \bmod m(1)
$$

$\mathrm{X}_{\mathrm{b}} \quad=$ bilangan acak ke-b

$\mathrm{p} \quad=$ faktor pengali

$\mathrm{X}_{\mathrm{b}-1} \quad=$ bilangan acak sebelumnya

$\mathrm{q}=$ penambahan nilai (increment)

$\mathrm{m} \quad=$ modulus

Dari rumus diatas, dapat dijelaskan bahwa $X_{b}$ adalah variable dari bilangan acak ke-b, dimana $\mathrm{p}$ dan q sebagai konstanta dan $\mathrm{m}$ sebagai batas maksimum dari bilangan acak[9].

Penentuan konstanta Linear Congruential Generator $(L C G)(\mathrm{p}, \mathrm{q}$ dan $\mathrm{m})$ digunakan sebagai acuan penilaian bilangan acak dalam memperoleh hasil[10].

Berikut contoh penerapan metode LCG pada aplikasi ini, yaitu:

1. Level $2 \times 3$

Pengacakan untuk 6 gambar dimana $\mathrm{p}=1, \mathrm{q}=7, \mathrm{~m}=6$, dan $\mathrm{X}(0)=2$. Maka perhitungannya:

$\mathrm{X}(0)=2$

$X(1)=(1(2)+7) \bmod 6=3$

$X(2)=(1(3)+7) \bmod 6=4$

$\mathrm{X}(3)=(1(4)+7) \bmod 6=5$

$X(4)=(1(5)+7) \bmod 6=0$

$X(5)=(1(0)+7) \bmod 6=1$

Hasil perhitungan yang telah diperoleh adalah $2,3,4,5,0,1$. Perhitungan ini berhasil dalam pengacakan sehingga bilangan tidak berulang.

2. Level $3 \times 3$

Bilangan acak gambar sebanyak 9 kali dimana $p=1, q=5, m=9$, dan $X(0)=6$. Maka perhitungannya:

$\mathrm{X}(0)=6$

$X(1)=(1(6)+5) \bmod 9=2$

$X(2)=(1(2)+5) \bmod 9=7$

$X(3)=(1(7)+5) \bmod 9=3$

$X(4)=(1(3)+5) \bmod 9=8$

$X(5)=(1(8)+5) \bmod 9=4$

$\mathrm{X}(6)=(1(4)+5) \bmod 9=0$

$X(7)=(1(0)+5) \bmod 9=5$

$X(8)=(1(5)+5) \bmod 9=1$

Dari perhitungan diatas, hasil yang diperoleh adalah 9, 7, 5, 3, 1, 8, 6, 4, 2. Urutan bilangan yang ada digunakan sebagai perumpamaan posisi potongan gambar yang tidak terjadi pengulangan.

\section{HASIL DAN PEMBAHASAN}

\subsection{Analisis Kebutuhan Perangkat}

Didalam perancangan game ini dibutuhkan beberapa perangkat yang akan digunakan, diantaranya: 


\subsubsection{Perangkat Keras}

Tabel 1. Spesifikasi Perangkat Keras

\begin{tabular}{|l|l|}
\hline \multicolumn{1}{|c|}{ Perangkat } & \multicolumn{1}{c|}{ Spesifikasi } \\
\hline Sistem Operasi & Windows 10 64-bit \\
\hline Prosesor & AMD A4-7210 APU \\
\hline RAM & $8 \mathrm{~GB}$ \\
\hline
\end{tabular}

\subsubsection{Perangkat Lunak}

Tabel 2. Spesifikasi Perangkat Lunak

\begin{tabular}{|l|l|}
\hline \multicolumn{1}{|c|}{ Perangkat } & \multicolumn{1}{c|}{ Fungsi } \\
\hline Affinity Designer & Mendesain rancangan asset \\
\hline Construct 2 & $\begin{array}{l}\text { Membangun logic dan } \\
\text { animasi permainan }\end{array}$ \\
\hline Draw.io & Membuat alur sistem \\
\hline Adobe Phonegap & Mengkonversi aplikasi \\
\hline
\end{tabular}

\subsection{Perancangan Aplikasi}

\subsubsection{Membuat Asset Permainan}

Pada tahap perancangan asset menggunakan aplikasi Affinity Designer yang kemudian akan dikonversi kedalam format PNG dan diimport kedalam aplikasi Construct 2.

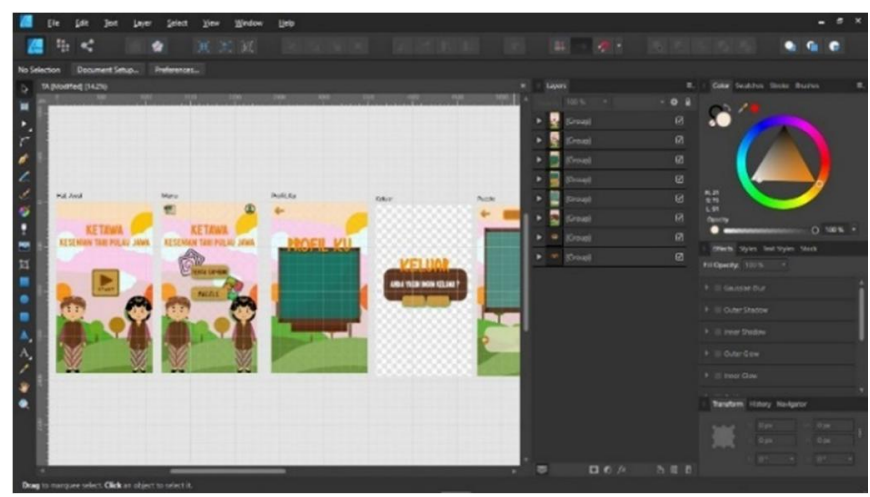

Gambar 3. Rancangan Asset Permainan

\subsubsection{Merancang UI Aplikasi}

Selanjutnya, pada tahap perancangan UI aplikasi menggunakan Construct 2. Pada perancangan ini aplikasi berisi layout menu awal, pilih level, belajar tari, profil perancang serta menu keluar aplikasi. 


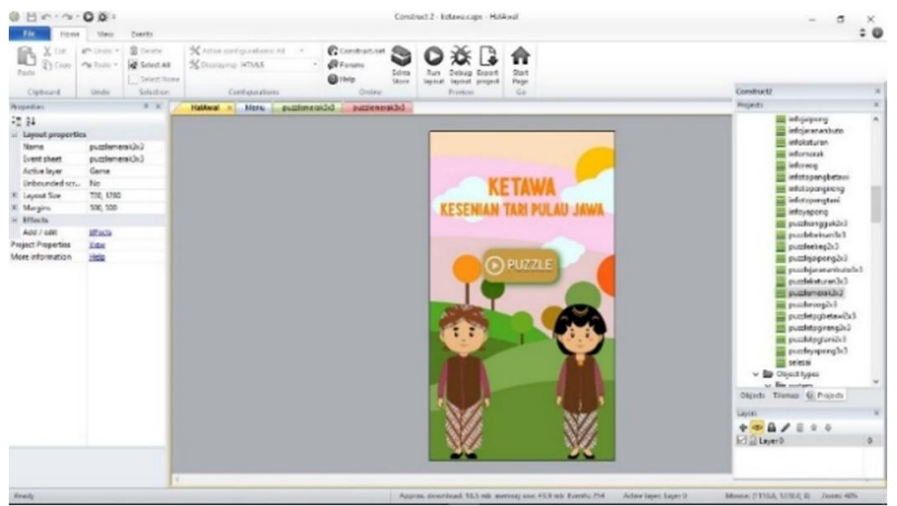

Gambar 4. Tampilan UI Aplikasi

\subsubsection{Membuat Logic dan Animasi Permainan}

Pada gambar 5 menampilkan logic dari alur pembuatan aplikasi untuk pengacakan gambar puzzle dan animasi tampilan yang telah dibuat.

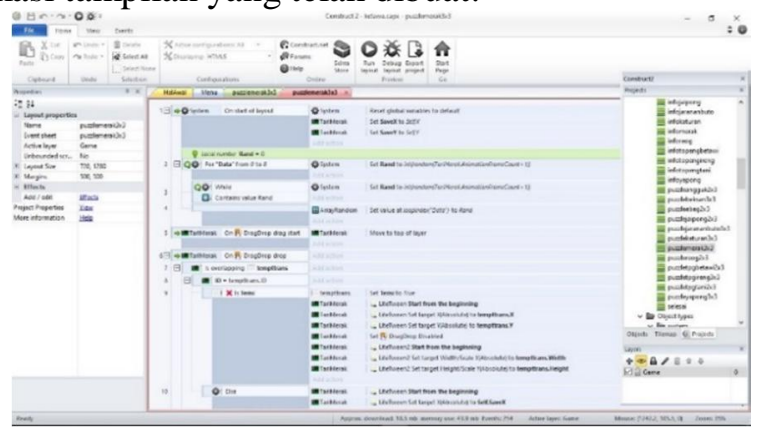

Gambar 5. Tampilan Logic dan Animasi

\subsection{Perancangan Aplikasi}

\subsubsection{Halaman Awal}

Pada saat aplikasi dijalankan halaman pertama yang muncul adalah menu awal dimana halaman ini berisi button puzzle yang jika diklik akan menampilkan halaman selanjutnya.

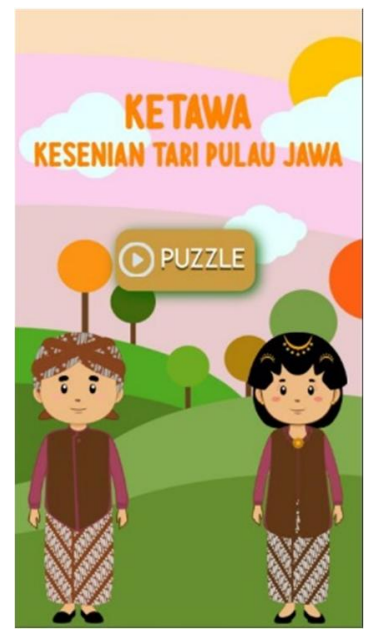

Gambar 6. Halaman Awal 


\subsubsection{Menu Level}

Setelah melewati halaman awal, pengguna dapat memilih level yang telah disediakan yaitu level $2 \times 3$ dan $3 \times 3$. Pada halaman ini juga terdapat button profil dan button keluar.

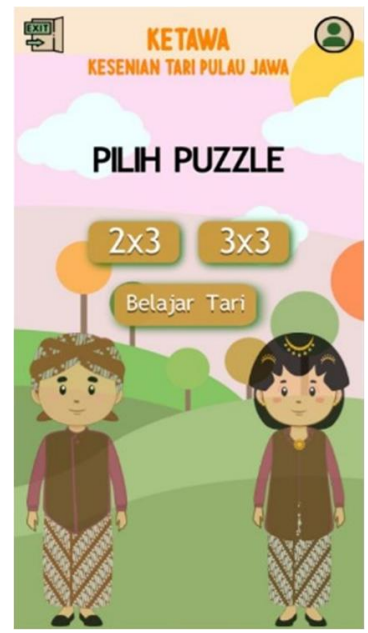

Gambar 7. Menu Level

\subsubsection{Level $2 \times 3$}

Tampilan ini menampilkan level 2x3, berisi potongan puzzle terdiri dari 6 gambar yang disajikan secara acak. Pengguna diharuskan menyusun puzzle hingga selesai kemudian dapat melanjutkan kegambar puzzle selanjutnya.

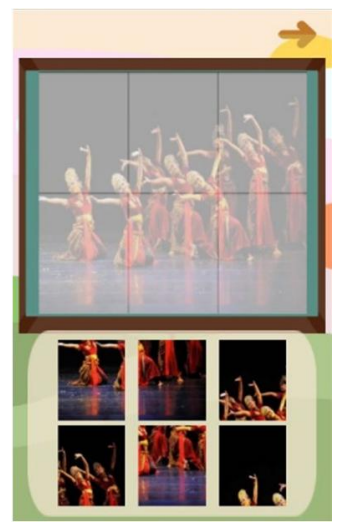

Gambar 8. Puzzle Awal 2x3

Gambar 9 menampilkan, tampilan pada saat gambar puzzle telah selesai tersusun. 


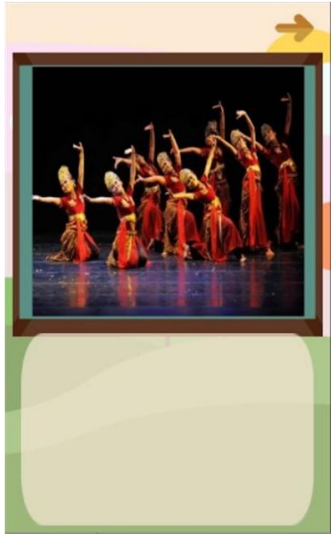

Gambar 9. Puzzle 2x3 Tersusun

\subsubsection{Level $3 \times 3$}

Level 3x3 menampilkan 9 potongan gambar yang akan disusun.

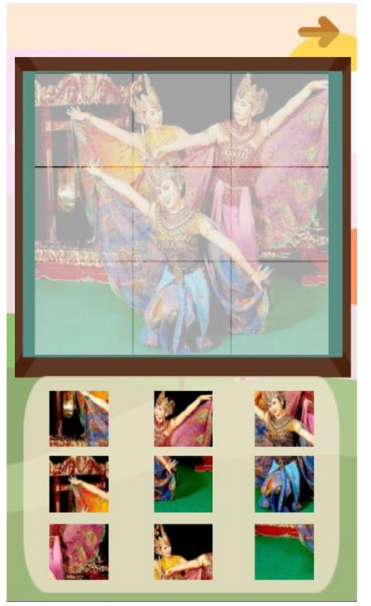

Gambar 10. Puzzle Awal 3x3

Ketika seluruh gambar puzzle selesai disusun, maka permainan akan berakhir dan akan kembali ke menu awal.

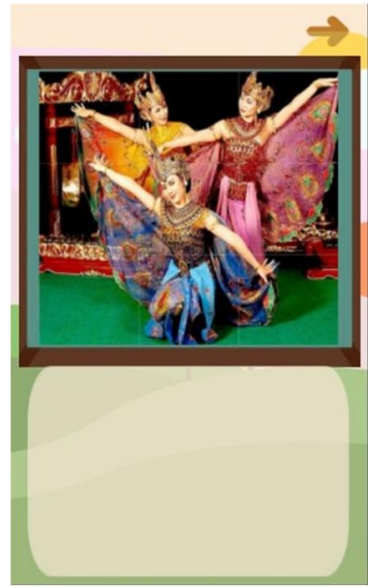

Gambar 11. Puzzle 3x3 Tersusun 


\subsubsection{Belajar Tari}

Gambar 12 menampilkan beberapa informasi singkat terkait dengan kesenian tari di Pulau Jawa.

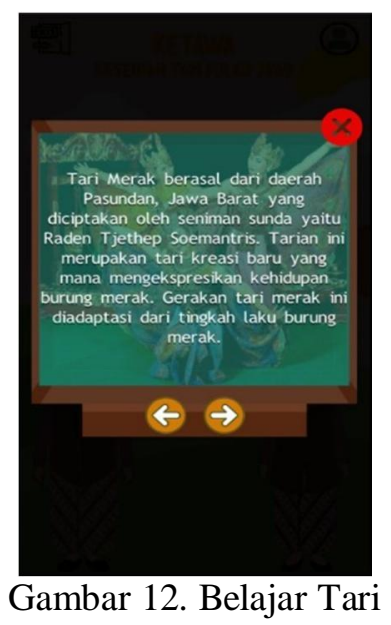

\subsubsection{Profil}

Pada halaman menu terdapat button profil yang jika diklik akan muncul papan berisi data diri perancang.

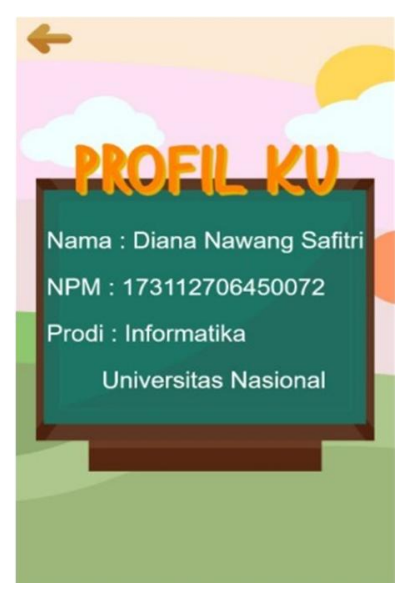

Gambar 13. Profil

\subsubsection{Keluar}

Saat memilih button keluar, pengguna akan dipastikan lagi untuk keluar atau tetap berada didalam aplikasi. 


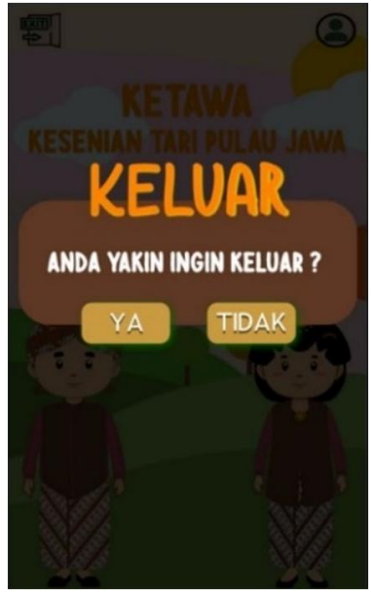

Gambar 14. Keluar

\subsection{Pengujian}

Tahap pengujian terhadap device atau perangkat digunakan sebagai tingkat keberhasilan aplikasi diberbagai spesifikasi perangkat.

Tabel 3. Pengujian Terhadap Device

\begin{tabular}{|c|c|c|}
\hline Perangkat & Sistem Operasi & Keterangan \\
\hline 1 & OS Android 10 & Berhasil \\
\hline 2 & OS Android 9.0 & Berhasil \\
\hline 3 & OS Android 8.0 & Berhasil \\
\hline 4 & OS Android 7.0 & Berhasil \\
\hline
\end{tabular}

Tahap pengujian pada penelitian ini menggunakan pengujian black box yang tertera pada tabel berikut:

Tabel 4. Hasil Pengujian Black Box

\begin{tabular}{|c|c|c|c|c|}
\hline No. & Layout & Aktivitas & Keterangan & Hasil \\
\hline \multirow[t]{2}{*}{1} & \multirow{2}{*}{ Layout Awal } & $\begin{array}{l}\text { Tampilan Halaman } \\
\text { Awal }\end{array}$ & $\begin{array}{l}\text { Menampilkan halaman awal } \\
\text { aplikasi }\end{array}$ & Berhasil \\
\hline & & Button Puzzle & Menampilkan halaman menu & Berhasil \\
\hline \multirow{3}{*}{2} & \multirow{3}{*}{$\begin{array}{c}\text { Menu Puzzle } \\
\text { 2x3 }\end{array}$} & Button 2x3 & $\begin{array}{l}\text { Menampilkan } \\
\text { puzzle dengan } 6 \text { potonganan } \\
\text { gambar }\end{array}$ & Berhasil \\
\hline & & Button lanjut & $\begin{array}{lll}\begin{array}{l}\text { Melanjutkan } \\
\text { selanjutnya }\end{array} & \text { ge } & \text { gambar } \\
\end{array}$ & Berhasil \\
\hline & & Button kembali & Kembali ke halaman menu & Berhasil \\
\hline 3 & $\begin{array}{l}\text { Menu Puzzle } \\
\quad 3 \times 3\end{array}$ & Button $3 \times 3$ & $\begin{array}{l}\text { Menampilkan } \\
\text { puzzle dengan } 9 \text { pormainan } \\
\text { gambar }\end{array}$ & Berhasil \\
\hline
\end{tabular}




\begin{tabular}{|c|c|c|c|c|}
\hline & & Button lanjut & $\begin{array}{l}\begin{array}{l}\text { Melanjutkan } \\
\text { selanjutnya }\end{array} \\
\end{array}$ & Berhasil \\
\hline & & Button kembali & Kembali ke halaman menu & Berhasil \\
\hline \multirow{4}{*}{4} & \multirow{4}{*}{$\begin{array}{l}\text { Menu Belajar } \\
\text { Tari }\end{array}$} & Menu belajar tari & $\begin{array}{ll}\text { Menampilkan } & \text { informasi } \\
\text { singkat mengenai kesenian } \\
\text { tari Pulau Jawa }\end{array}$ & Berhasil \\
\hline & & Button lanjut & $\begin{array}{l}\text { Beralih ke informasi tari } \\
\text { selanjutnya }\end{array}$ & Berhasil \\
\hline & & Button kembali & $\begin{array}{l}\text { Beralih ke informasi tari } \\
\text { sebelumnya }\end{array}$ & Berhasil \\
\hline & & Button keluar & Kembali ke halaman menu & Berhasil \\
\hline 5 & Profil & Button profil & $\begin{array}{l}\text { Menampilkan papan profil } \\
\text { perancang }\end{array}$ & Berhasil \\
\hline 6 & Keluar & Button keluar & Keluar dari aplikasi & Berhasil \\
\hline
\end{tabular}

\section{KESIMPULAN}

Dari perancangan game yang sudah dibangun, dapat diperoleh kesimpulan bahwa:

1. Metode Linear Congruential Generator ( $L C G$ ) dinilai cocok diterapkan pada game puzzle karena metode tersebut berfungsi untuk mengacak potongan gambar puzzle pada awal permainan meskipun terdapat beberapa kali pengulangan karena itu merupakan sifat dari metode $L C G$.

2. Game puzzle ini mampu membantu pengguna dalam menambah informasi dan wawasan mengenai tarian di Pulau Jawa.

\section{SARAN}

Saran yang bisa diberikan yaitu untuk lebih meningkatkan kualitas, menambahkan fiturfitur didalam aplikasi, dan memperbarui desain agar terlihat lebih menarik. Dapat juga untuk lebih dikembangkan mengenai batasan masalah yang ada agar dapat lebih beragam materi yang akan dibuat.

\section{DAFTAR PUSTAKA}

[1] A. K. Streit. 2012, Analisa Permainan Edukatif Berbentuk Puzzle Dalam Bentuk Ilustrasi Tarian Indonesia, Vol. 1, pp. 20-30.

[2] R. A. Krisdiawan. 2018, Implementasi Model Pengembangan Sistem GDLC dan Algoritma Linear Congruential Generator pada Game Puzzle, Nuansa Inform., Vol. 12, No. 2, pp. 1-9.

[3] H. Trimantara and N. Mulya. 2019, Mengembangkan Bahasa Anak Usia 4-5 Tahun Melalui Alat Permainan Edukatif Puzzle, Al-Athfaal J. Ilm. Pendidik. Anak Usia Dini, Vol. 2, No. 1, pp. 25-34. 
[4] A. Šag and T. Orehovacki. 2019, Development of 2D Game with Construct 2, 2019 42nd Int. Conv. Inf. Commun. Technol. Electron. Microelectron. MIPRO 2019 - Proc., pp. $1647-1652$.

[5] B. Arifin, Z. -, and A. Sifaunajah, 2018, Aplikasi Game Puzzle Pengenalan Perangkat Komputer Berbasis Android, Saintekbu, Vol. 10, No. 2, pp. 42-51.

[6] H. E. Putra and K. Harianto. 2018, Implementasi Linear Congruential Generator untuk Pengacakan Gambar pada Permainan Puzzle, SATIN - Sains dan Teknol. Inf., Vol. 4, No. 1, p. 89.

[7] A. Isaksen, D. Wallace, A. Finkelstein, and A. Nealen. 2017, Simulating Strategy and Dexterity for Puzzle Games, 2017 IEEE Conf. Comput. Intell. Games, CIG 2017, pp. 142-149.

[8] K. Ramadhan, L. W. Astuti, and D. A. Verano. 2015, Game Edukasi Tebak Gambar Bendera Negara Menggunakan Metode Linear Congruential Generator (LCG) Berbasis Android, J. Inform. Glob., Vol. 6, No. 1, pp. 27-32.

[9] E. P. Malau and A. Julianti. 2018, Aplikasi Edugame Menggunakan Linear Congruent Method dan Algoritma Flood Fill, Vol. 03, No. 479, pp. 2548-1916.

[10] B. Prasetyo, I. Agustina, and M. Gufroni, 2017, Perancangan Game Puzzle Pemadam Kebakaran Menggunakan Metode Linear Congruential Generator (LCG), JOINTECS (Journal Inf. Technol. Comput. Sci., Vol. 2, No. 2, 